\title{
Use of portable partitions with high-efficiency particulate air filters in the endoscopy unit
}

Upper gastrointestinal endoscopy is one of the procedures with a high risk for spreading SARS-CoV-2 because the virus infects via aerosol transmission [1]. When Endoscopic procedures performed on patients infected with SARS-CoV-2 should be conducted in a negative-pressure room [2,3]. Testing of SARS-CoV-2positive patients may be routine because they are asymptomatic and a significant number of these individuals also exhibit gastrointestinal symptoms [2]. Several strategies have been suggested to reduce the risk of transmitting the infection during gastrointestinal endoscopy [4].

We have placed in our endoscopy units portable partitions with high-efficiency particulate air (HEPA) filters. The HEPA designation requires that a filter capture $99.97 \%$ of particles $\geq 0.3 \mu \mathrm{m}$ in size in that pass through it. Knowledge of HEPA filter functionality and prior Centers for Disease Control and Prevention (CDC) guidance for SARS-CoV-1 suggest the theoretical efficacy of HEPA filters for removing airborne SARS-CoV-2 [5]. To arrange the HEPA partitions properly, we evaluated the efficacy of placement by using $\mathrm{CO}_{2}$ generated from dry ice. Partitions with filters were placed on both sides of the endoscopy unit ( $\mathbf{F i g} \mathbf{1}$ ). The partition placed near the patient's back draws in air flowing over the patient, whereas the partition placed on the patient's ventral side draws in air from the adjacent endoscopic unit and its output is filtered air. By adjusting the position of the partition and the operator, airflow can be directed toward the patient's back ( $>$ Fig. 2 and $>$ Video 1 ). Combination devices with mechanical protection like the C-Cube [4] and a clean partition may be one countermeasure for ensuring the removal of aerosols containing SARS-CoV-2.

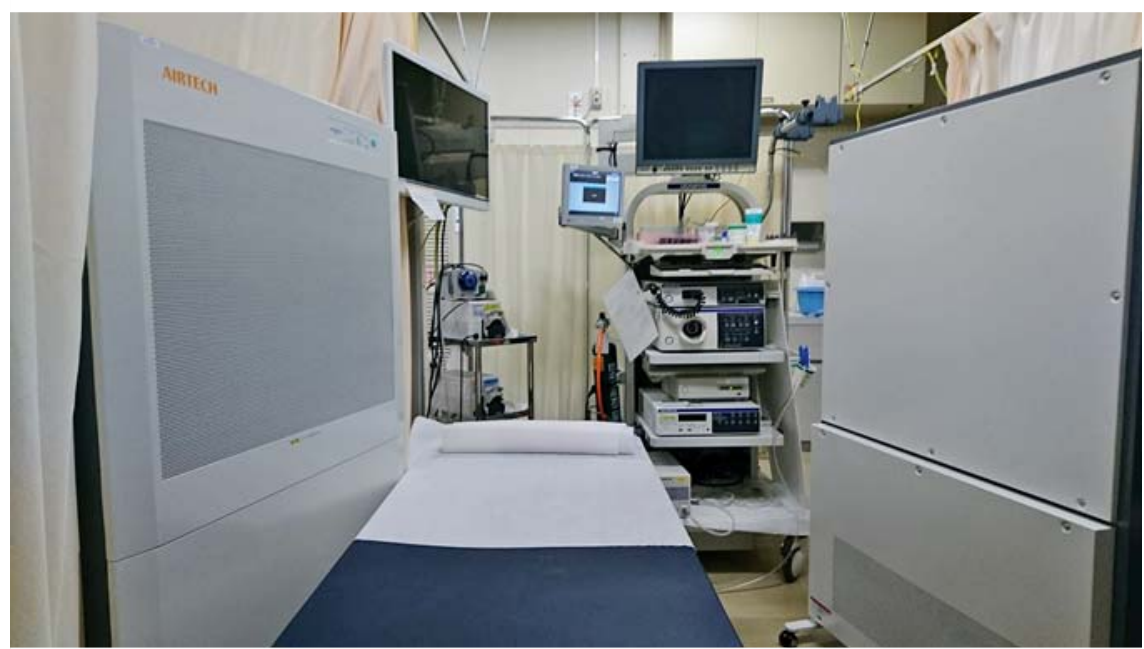

Fig. 1 Portable partitions with high-efficiency particulate air (HEPA) filters were placed in the endoscopy unit.

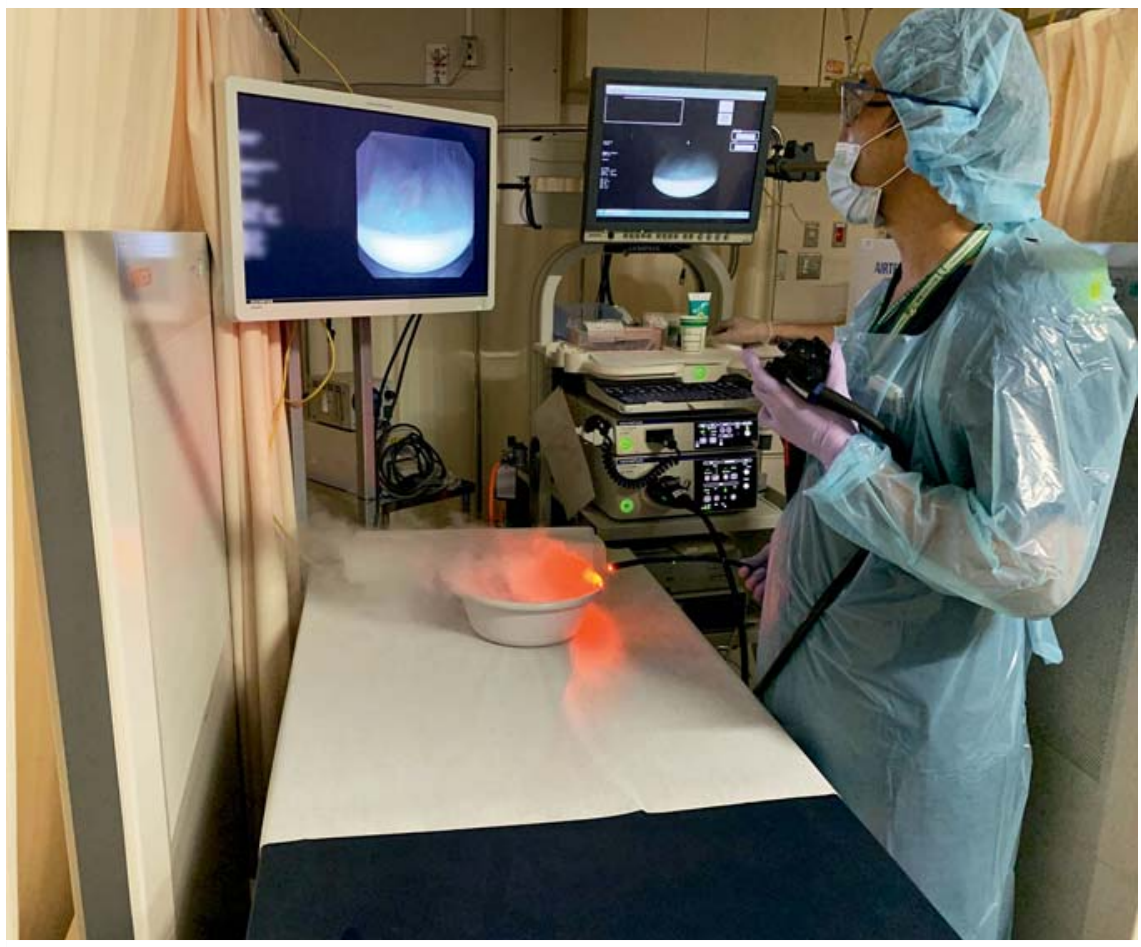

- Fig. 2 The efficacy of portable partitions. $\mathrm{CO}_{2}$ gas was evaluated by pouring water on dry ice in the tub. Airflow can be directed toward the patient's back by using the portable partitions. 


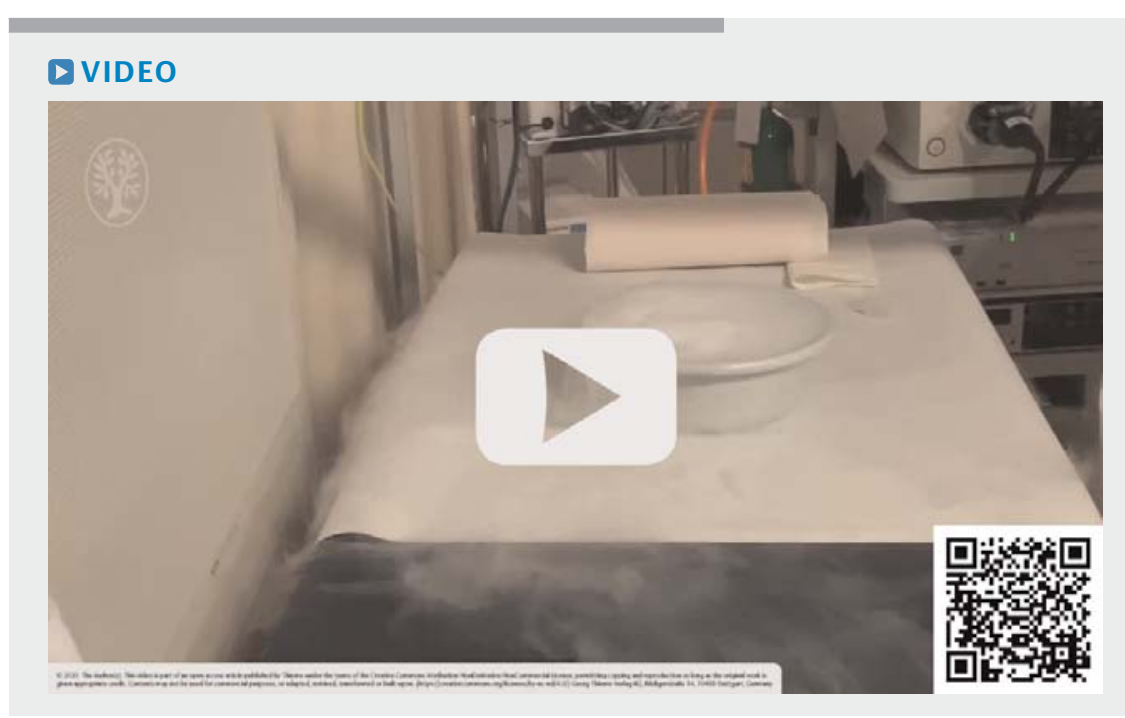

- Video 1 The efficacy of portable partitions. By adjusting the position of the partition and the operator, airflow can be directed toward the patient's back. During the recording of this video, no air insufflation from the endoscope was used.

\section{Competing interests}

The authors declare that they have no conflict of interest.

The authors

\section{Hiroyuki Fujimura', Jun Nishikawa², Takeshi} Okamoto ${ }^{1}$, Atsushi Goto ${ }^{1}$, Koichi Hamabe', Isao Sakaida ${ }^{1}$

1 Department of Gastroenterology and Hepatology, Yamaguchi University Graduate School of Medicine, Ube, Japan

2 Faculty of Laboratory Science, Yamaguchi University Graduate School of Medicine, Ube, Japan
[1] Repici A, Maselli R, Colombo M et al. Coronavirus (COVID-19) outbreak: what the department of endoscopy should know. Gastrointest Endosc 2020; 9: 192-197

[2] Chiu PWY, Ng SC, Inoue $\mathrm{H}$ et al. Practice of endoscopy during COVID-19 pandemic: position statements of the Asian Pacific Society for Digestive Endoscopy (APSDE-COVID statements). Gut 2020; 69: 991-996

[3] Calderwood AH, Day LW et al. ASGE Quality Assurance in Endoscopy Committee. ASGE guideline for infection control during $\mathrm{Gl}$ endoscopy. Gastrointest Endosc 2018; 87: 1167-1179

[4] Traina M, Amata M, Granata A et al. The CCube: an endoscopic solution in the time of COVID-19. Endoscopy 2020; 52: E351-E352

[5] Christopherson DA, Yao WC, Lu M et al. High-efficiency particulate air filters in the era of COVID-19: Function and efficacy. Otolaryngol Head Neck Surg 2020; 163 1153-1155 [194599820941838]

\section{Bibliography}

Endoscopy International Open 2021; 09: E278-

E279

DOI 10.1055/a-1322-2761

ISSN 2364-3722

(c) 2021. The Author(s).

This is an open access article published by Thieme under the terms of the Creative Commons Attribution-NonDerivativeNonCommercial License, permitting copying and reproduction so long as the original work is given appropriate credit. Contents may not be used for commecial purposes, or adapted, remixed, transformed or built upon. (https:// creativecommons.org/licenses/by-nc-nd/4.0/)

Georg Thieme Verlag KG, Rüdigerstraße 14, 70469 Stuttgart, Germany

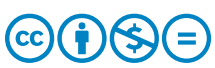

